\title{
A Current-Controlled PWM Bipolar Power Supply for a Magnet Load*
}

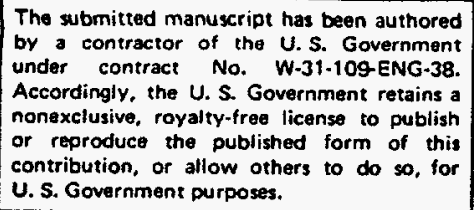

\section{Y. G. Kang, IEEE Member and D. G. McGhee, IEEE Member}

\author{
Advanced Photon Source Division \\ Argonne National Laboratory \\ Argonne, IL 60439
}

Abstract - The Advanced Photon Source, at Argonne National Laboratory will produce the world's brightest $x$-ray beams when it is complete. A number of correction magnets are used to maintain proper beam position. Basically, two different types of bipolar power supplies are used for all the correction magnets: one requires dc correction only, and the other requires dc and ac correction. Normally linear-mode power amplifiers would be used for the bipolar power supplies. However, linear-mode power amplifiers dissipate a substantial amount of power as heat, resulting in poor efficiency for their large size. In addition, most commercial bipolar power supplies are linear-mode and available for lower power levels. Therefore, for higher power levels it was necessary to design a bipolar power supply that uses switch-mode power conversion. This paper describes a control technique for a pulse-width-modulated bipolar power supply, which can deliver a controlled current, de plus ac. to a correction magnet. A design example of a $150 \mathrm{~A}$ bipolar power supply is presented.

\section{INTRODUCTION}

Argonne National Laboratory's (ANL) Advanced Photon Source (APS), currently under construction, will produce the world's brightest $x$-ray beams. In order to maintain the beam's proper position, a number of correction magnets are used $[1,2]$. In the Storage Ring, displacement of the quadrupole magnets due to low frequency vibration below $25 \mathrm{~Hz}$ is the most significant factor affecting the stability of the positron closed orbit. The primary external source of low-frequency vibration is the ground motion of approximately $20 \mu \mathrm{m}$ amplitude, with frequency components concentrated below $10 \mathrm{~Hz}$. These low-frequency vibrations can be corrected by using correction magnets, whose field strengths are controlled individually through the feedback loop comprising the beam position monitoring system.

The correction field required could be either positive or negative. Thus for all the correction magnets, bipolar power supplies (BPSs) are required to produce both polarities of correction fields. Basically, two different types of bipolar power supplies are used for all the APS correction magnets. One requires $\mathrm{dc}$ correction only, and the other requires $\mathrm{dc}$ and ac correction. For example, the correction magnet current for the Storage Ring consists of a dc component and an ac component as shown in Fig. 1. Normally a linear-mode power amplifier would be used for the BPS. Since the linear-mode power amplifier dissipates a substantial amount of power as heat, the efficiency is very poor and the size of the amplifier is large. Most commercial BPSs are linear-type and available for lower power levels (under $400 \mathrm{~W}$ ). Therefore, it was necessary to design BPSs using the switch-mode power conversion for the higher power levels required at ANL. There are a number of articles for current-controlled pulse-width-modulated (PWM) inverters mainly for motor drive applications [3 - 8]. It is noted that to generate beams in accelerator applications, high performance magnet power supplies are required. In reference [9], a bipolar power supply is configured with two half-bridge filtered PWM current sources operating in the master-slave mode. One half-bridge delivers a positive current and the other delivers a negative current. One base unit, a master and a slave, delivers $20 \mathrm{~A}$ output current. Using a single master, up to 20 slaves can be driven for higher power applications. The control of this BPS is rather complex. In order to maximize reliability, the goal was to make the BPS as simple as possible. This paper deals with the design and development of a BPS using switch-mode power conversion for a magnet load. A 150A BPS has been designed, prototyped, and tested, and approximately 650 units are being manufactured. The design example and key experimental results are provided.

\section{CIRCUIT DESCRIPTION AND OPERATION PRINCIPLE}

Figure 2 shows the simplified circuit configuration of a bipolar power supply considered here. The topology is a full-bridge converter/inverter, which can be a dc-to-dc converter for dc operation or a dc-to-ac inverter for ac operation. A set of switches, Q1 and Q4, is used for one direction of the load current (say positive current), and the other set of switches, Q2 and Q3, for a negative portion of the load current. $L_{m}$ and $R_{m}$ represent the inductance and resistance of a correction magnet. Since the inductance value of a magnet is relatively large in our particular application, no output filter is considered. In a typical voltage source inverter, switches Q1 and Q4 (Q2 and Q3) are switched on and off simultaneously according to PWM signals, resulting in switching losses for two switches. However, in order to reduce switching losses, it is preferable to control only one switch at a time rather than controlling both upper and lower switches (i. e., Q1 \& Q4 or Q2 \& Q3) simultaneously.

\section{A. DC operation}

For dc operation, there are two modes of operation, and the operation principle is exactly the same as a dc/dc Buck converter. For a positive magnet current, switches Q1 and Q4 are closed to deliver power to the load for a period of $T_{\text {on }}$ (Mode 1). The circuit for Mode 1 operation and its equivalent circuit are shown in Fig. 3. After the period of $\mathrm{T}_{\mathrm{on}}$, the upper switch $\mathrm{Q1}$ is opened for a period of $\mathrm{T}_{\text {off }}$, while the lower switch $\mathrm{Q} 4$ remains closed (Mode 2). Figure 4 shows Mode 2 operation and its equivalent circuit. When Q1 is opened for $T_{\text {off }}$, the magnet current freewheels through the still closed switch $\mathrm{Q} 4$ and diode D3. For a negative magnet current, switches Q2 and Q3 and diode D4 are operated in a symmetrically

* Work supported by the U.S. Department of Energy, Office of Basic Energy Sciences under Contract

No. W-31-109-ENG-38. 


\section{DISCLAIMER}

This report was prepared as an account of work sponsored by an agency of the United States Government. Neither the United States Government nor any agency thereof, nor any of their employees, make any warranty, express or implied, or assumes any legal liability or responsibility for the accuracy, completeness, or usefulness of any information, apparatus, product, or process disclosed, or represents that its use would not infringe privately owned rights. Reference herein to any specific commercial product, process, or service by trade name, trademark, manufacturer, or otherwise does not necessarily constitute or imply its endorsement, recommendation, or favoring by the United States Government or any agency thereof. The views and opinions of authors expressed herein do not necessarily state or reflect those of the United States Government or any agency thereof. 


\section{DISCLAIMER}

Portions of this document may be illegible in electronic image products. Images are produced from the best available original document. 


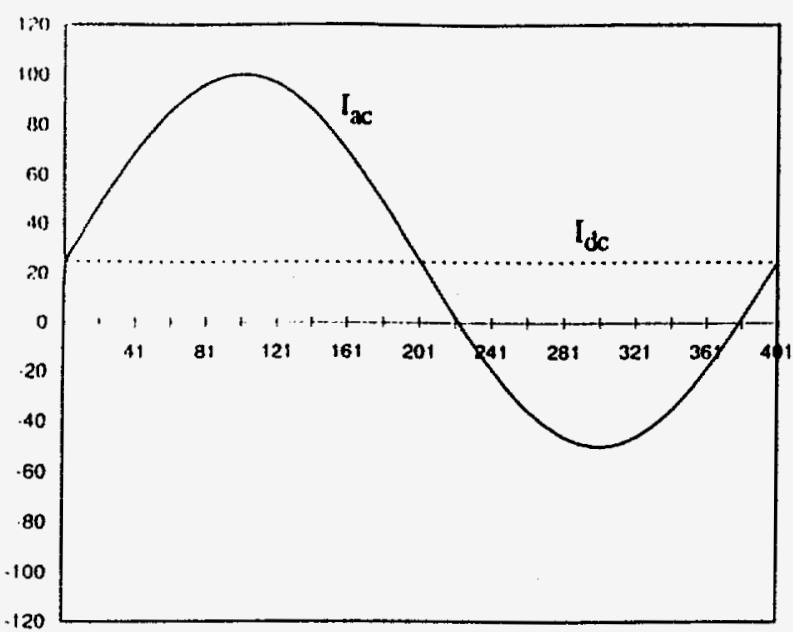

Fig. 1: Example of a correction magnet current.

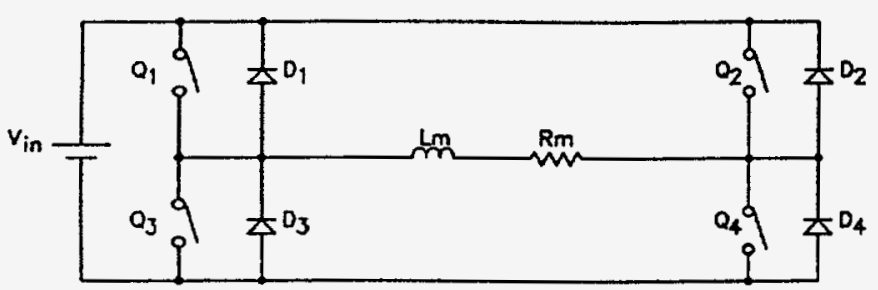

Fig. 2: Simplified circuit of a bipolar power supply.

opposite manner. It is noted that by controlling only one switch at a time according to the PWM signal, not only can we reduce the switching loss by half but we can also maintain the Buck converter operation principle. In other words, if $\mathrm{Q} 1$ and $\mathrm{Q} 4$ are opened simultaneously, then the stored energy in the magnet will be returned back to the source during the off time, $T_{\text {off }}$. Hence, the converter does not operate as a Buck converter.

\section{B. AC operation}

For ac operation, there is an additional mode of operation. For the positive di/dt, it is operated in the same manner as dc operation explained above. In order to increase the magnet current, the ON time of the upper switch Q1 (Q2) is in general longer than its OFF time (i.e., $T_{\text {on }}>T_{\text {off }}$ ). On the other hand, for the negative di/dt, the OFF time of the upper switch Q1 (Q2) is longer than the on time (i.e., $\mathrm{T}_{\text {off }}>\mathrm{T}_{\text {on }}$ ) in order to decrease the magnet current. It is pointed out that even with $100 \%$ off time (i.e., Q1 is completely OFF with Q4 ON), the magnet current does not decay fast enough to follow the reference signal due to the large time constant of the magnet. Figure 6 shows the magnet current decay with Q1 (Q2) OFF and $Q 4(Q 3)$ ON $\left(T_{\text {on }}=0\right)$. Therefore, it is necessary to introduce another mode of operation (Mode 3) by opening the switch Q4 (Q3). Hence, in Mode 3 operation, as shown in Fig. 5, the stored energy in the magnet returns to the source via diodes D2 and D3, resulting in faster decay of the magnet current. Figure 7 shows the magnet current decay with both $\mathrm{Q} 1(\mathrm{Q} 2)$ and $\mathrm{Q4}(\mathrm{Q} 3)$ OFF simultaneously. Note that in this ac operation (Fig. 8) only upper switch Q1 (Q2) is controlled according to the PWM signal until the magnet current no longet keeps tracking the reference signal while lower switch Q4 (Q3) remains ON, and only lower switch Q4 (Q3) is controlled while upper switch Q1 (Q2) remains OFF. Hence, only one switch is controlled at a time for the ac operation, too.

The unregulated dc input bus voltage, $V_{i n}$, is the minimum required value to reduce the output ripple current without using any output filter, and is determined by the following expression:

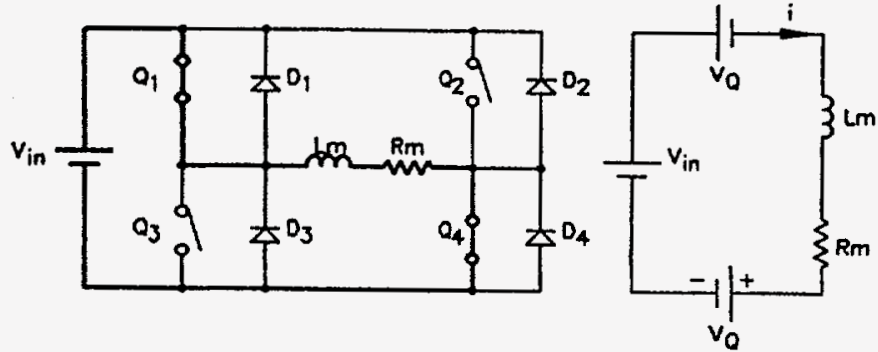

(a)

(b)

Fig. 3: Mode 1 operation and its equivalent circuit.

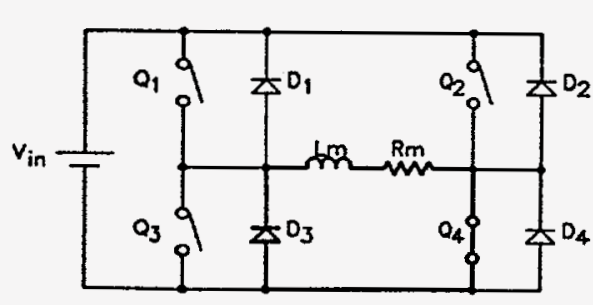

(a)

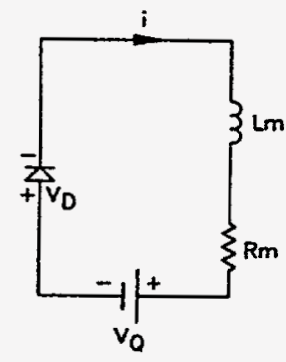

(b)
Fig. 4: Mode 2 operation and its equivalent circuit.

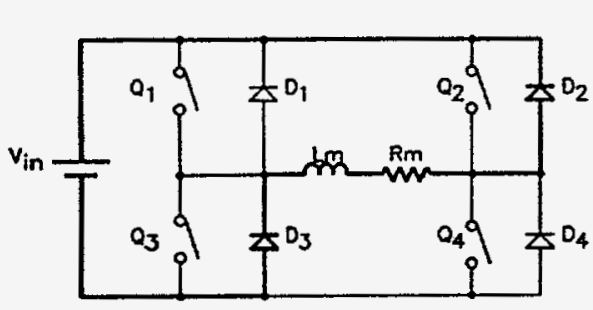

(a)

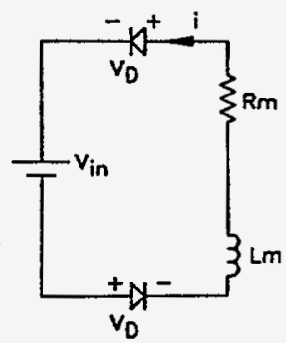

(b)
Fig. 5 : Mode 3 operation and its equivalent circuit.

$$
V_{\text {in }}=I_{p k}\left[\left(\omega L_{m}\right)^{2}+R_{m}^{2}\right]^{1 / 2} \sin (\omega t+\phi)+I_{d c} R_{m}
$$

where $I_{p k}=$ peak value of the ac current and $\omega=2 \pi f(f=$ reference frequency).

\section{ANALYSIS}

Referring to Fig. 2, the steady-state analysis of the circuit for a positive magnet current is carried out in the following manner.

\section{A. Mode 1 operation:}

For $0 \leq t \leq T_{o n}:\left(T_{o n}=\right.$ the conduction time of both switches $Q 1$ and Q4)

Figure 3 (b) shows the equivalent circuit when switches Q1 and Q4 are closed. Then, a differential equation for the period can be written as:

$$
V_{\text {in }}=L_{m} \frac{d i(t)}{d t}+R_{m} i(t)+2 V_{Q}
$$

where

$$
V_{Q}=\text { forward voltage drop of a switch. }
$$

By solving (2) for the current $i(t)$, we get 


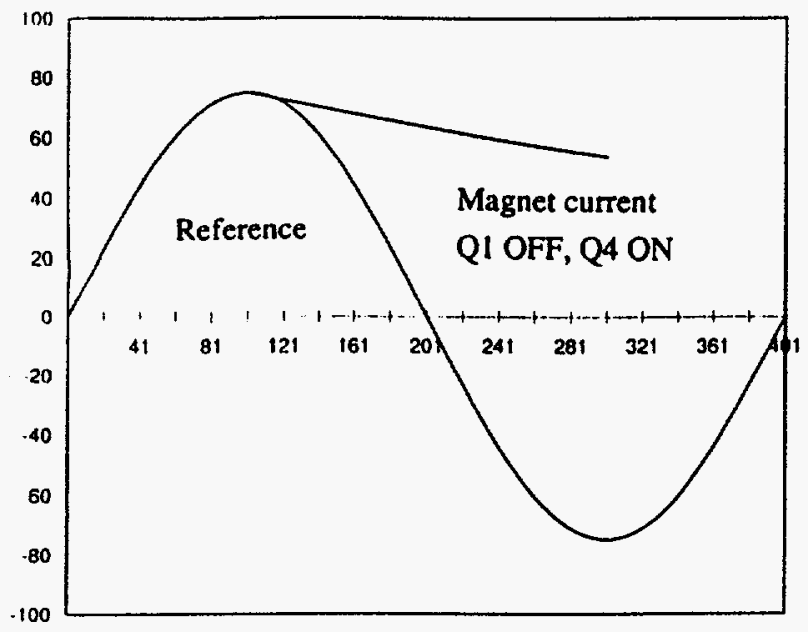

Fig. 6: Magnet current for negative di/dt with Q1 OFF and $\mathrm{Q} 4 \mathrm{ON}$.

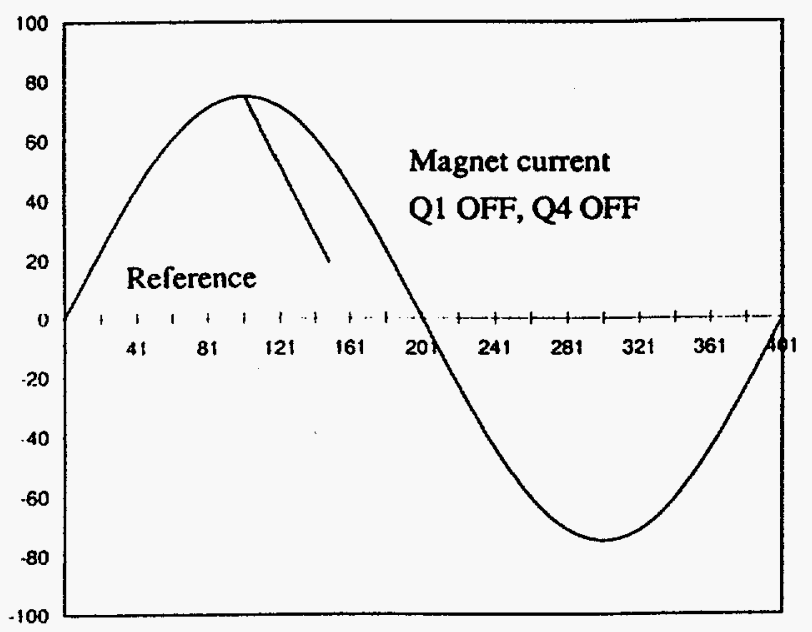

Fig. 7 : Magnet current for negative di/dt with both Q1 and Q4 OFF.

$$
i(t)=\frac{V_{i n}-2 V_{Q}}{R_{m}}\left(1-e^{-\tau t}\right)-I_{L O} e^{-\tau t}
$$

where $\quad I_{L 0}=$ initial magnet current at $t=0$ and $\tau=\frac{R_{m}}{L_{m}}$.

B. Mode 2 operation:

For $T_{\text {on }} \leq t \leq T_{s}:\left(T_{s}=T_{\text {on }}+T_{\text {off }}=\right.$ one switching period $)$

During this period switch $Q 4$ remains $O N$ and the anti-parallel diode $\mathrm{D} 3$ is conducting. Then the magnet current freewheels, and the equivalent circuit is shown in Fig. 4 (b). Thus, a differential equation for the period can be written as:

$$
0=L_{m} \frac{d i(t)}{d t}+R_{m} i(t)+V_{Q}+V_{D}
$$

where $\quad V_{D}=$ forward voltage drop of a diode.

The solution of (4) for $i(t)$ is given by

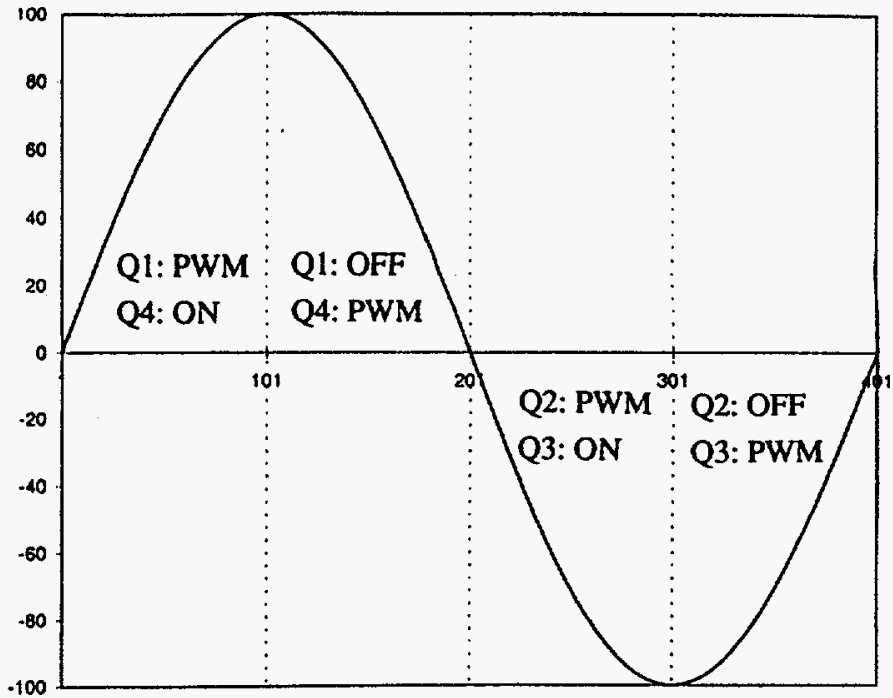

Fig. 8 : Switching actions for AC operation

$$
i(t)=I_{L 1} e^{-\tau t}-\frac{V_{0}+V_{n}}{R_{m}}\left(1-e^{-\tau t}\right)
$$

where

$$
\mathrm{I}_{\mathrm{L} 1}=\text { magnet current at } \mathrm{t}=\mathrm{T}_{\mathrm{on}} \text {. }
$$

The average voltage of the magnet, $V_{o(d c)}$, for a dc operation is determined by:

$$
\begin{aligned}
V_{O(d c)} & =\left(V_{\text {in }}-2 V_{Q}\right) \delta-\left(V_{Q}+V_{D}\right)(1-\delta) \\
& =\left(V_{\text {in }}+V_{D}-V_{Q}\right) \delta-\left(V_{Q}+V_{D}\right)
\end{aligned}
$$

where

$$
\delta=\text { duty ratio }=T_{\text {on }} /\left(T_{\text {on }}+T_{\text {off }}\right) \text {. }
$$

\section{Mode 3 operation:}

During this period both switches Q1 and Q4 remain OFF and the anti-parallel diodes D2 and D3 are conducting. Thus the stored energy in the magnet returns to the source, resulting in the faster decay of the magnet current. From the equivalent circuit as shown in Fig. 5(b), a differential equation for this period can be written as:

$$
V_{\text {in }}=-\left(L_{m} \frac{d i(t)}{d t}+R_{m} i(t)+2 V_{D}\right)
$$

By solving (7) for the current $i(t)$, we get

$$
i(t)=\frac{V_{\text {in }}-2 V_{Q}}{R_{m}}\left(1-e^{-\tau t}\right)-I_{L O} e^{-\tau t}
$$

where

$$
\mathrm{I}_{\mathrm{LO}}=\text { initial condition. }
$$

\section{DESIGN EXAMPLE}

An example of design and development of a 150A BPS is given in this section. The design criteria are as follows:
a. Input dc bus voltage :
$70 \mathrm{~V}+10 \% /-15 \%$
b. Maximum output current :
* Maximum ac component :
* dc offset current :
c. Magnet inductance :
d. Magnet resistance : 


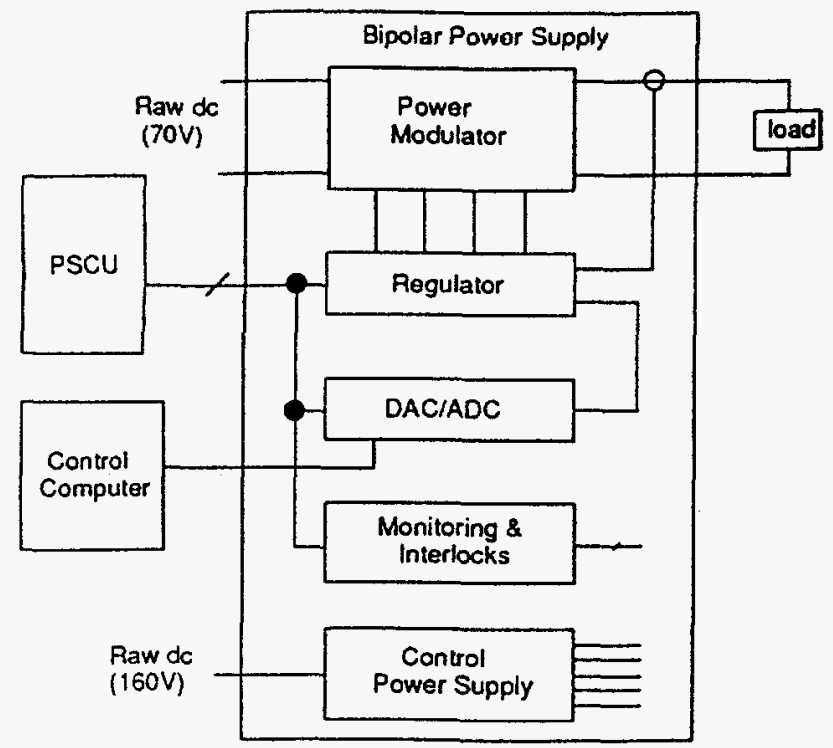

Fig. 9: Simplified block diagram of the BPS.
e. Maximum dc output voltage :
$20 \mathrm{~V}$
f. Maximum output power :
$3 \mathrm{~kW}$
g. Ripple current :
h. Stability :
i. Reference resolution :
0.15 A (peak-to-peak)
$+/-300$ ppm of $I_{o, \max }$
16-bit

\section{A. System Description}

Figure 9 shows the simplified block diagram of a bipolar power supply designed at ANL. It consists of a power modulator (main power section), four Euro-cards for the regulator, digital-to-analog and analog-to-digital converters (DAC/ADC), converter and magnet monitoring and interlocks, and a control (or auxiliary) power supply board. This BPS is water-cooled: The power supply control unit (PSCU) contains the intelligence that interfaces directly to each power supply hardware for control, monitoring, and communicating to the host computer. One PSCU can control as many as eight BPSs.

\section{B. Main Power Section}

Figure 10 shows the simplified main power section of the BPS. The switching frequency is $20 \mathrm{kHz}$ synchronized with the main system clock. The regulation is achieved by the pulse-widthmodulation (PWM) method. Two dual packages of Insulated Gate Bipolar Transistors (IGBTs) are used for the switching devices due to their ruggedness and simple drive requirement. The IGBT body diodes are utilized for the anti-parallel diodes. $L_{m}$ and $R_{m}$ represent the inductance and resistance of a correction magnet. The required magnet current consists of a dc component and an ac component. The amplitude of the ac component varies from 0 to $75 \mathrm{~A}$ (peak) and its frequency varies from 0 to $25 \mathrm{~Hz}$. The dc component could be from 0 to $+/-150 \mathrm{~A}$, depending on the ac component. The total magnitude of $\mathrm{dc}$ and ac current does not exceed 150A.

In order to regulate the magnet current, the ramp comparison method and PI controller are used. The magnet current information is fed back to an error amplifier input via a current measuring device as the feedback signal, $V_{f}$, and is compared with the reference voltage, $V_{r}$, which is provided by a digital-to-analog converter (DAC). A $2 \mathrm{~m} \Omega$ shunt resistor is used for the current measuring device. Since the current loop responds slowly to the input voltage variation due to the large time constant of a correction magnet, the voltage-feedforward technique, which varies the ramp slope, is used

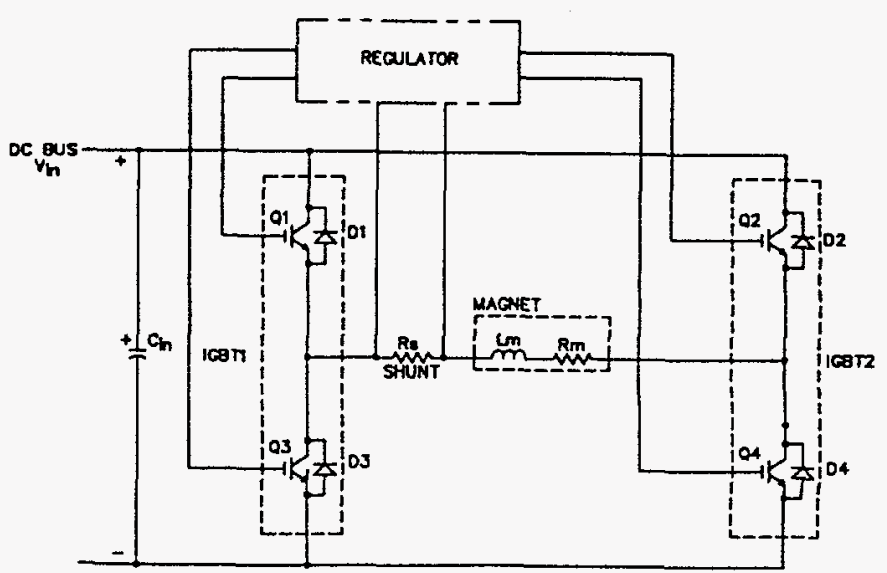

Fig. 10: Main power section.

in the regulator circuit for constant volt-second operation to the input variation. The required dc input bus voltage is determined from (1) as follows and is provided by a separate ac/dc rectifier.

$$
\begin{aligned}
V_{\text {in }} & =75\left[(2 \pi \times 25 \times 0.004)^{2}+0.13^{2}\right]^{1 / 2} \sin (\omega t+\phi)+75 \times 0.13 \\
& =75[0.64]+9.75=58[\mathrm{~V}]
\end{aligned}
$$

\section{Regulator}

Figure 11 shows the simplified regulator circuit used to generate gating signals. The reference signal, $\mathrm{V}_{\mathrm{r}}$, from a DAC is 0 to $+10 \mathrm{~V}$ for the positive magnet current and 0 to $-10 \mathrm{~V}$ for the negative current. A polarity signal, which determines a set of switches to be controlled, is derived from the error voltage signal by using a comparator. A logic high signal, which selects switches Q1 and Q4, is obtained for a positive value. Similarly, a logic low signal, which selects switches Q2 and Q3, is obtained for a negative value. The feedback signal, $V_{f}$, is provided from a current measuring device. The voltage developed across a $2 \mathrm{~m} \Omega$ shunt resistor is amplified by an isolation amplifier to produce $+10 \mathrm{~V}(-10 \mathrm{~V})$ for maximum positive (negative) current. The output of the error amplifier, $V_{e}$, is compared with a $10 \mathrm{~V}$ ramp signal, $\mathrm{V}_{\mathrm{s}}$, at a comparator generating a pulse train. This PWM signal is combined with the polarity signal using an AND gate to determine which switch, Q1 or Q2, is to be controlled. The maximum duty cycle could be $100 \%$, including $\mathrm{dc}$ offset current and ac current.

\section{DAC/ADC}

The reference signal for the regulator card is provided by a 16bit DAC, and the magnet current information (feedback voltage) is converted to digital information by a 20 -bit $A D C$ to be used for monitoring. The DAC's input values are set by an input counter, which has three optically coupled input signals: one to reset it to zero for soft start, a second to increment it one bit at a time, and a third to decrement it one bit at a time. These input values are from the PSCU which also serially clocks out the 16 most significant bits from the DAC. For dynamic correction, the DAC is loaded directly by the control computer in a serial-to-parallel manner.

\section{E. Control for Correction Magnets}

Figure 12 shows the simplified block diagram of a control scheme of correction magnet power supplies for the storage ring. The PSCU communicates to each power supply using optically coupled digital signals and differential shielded twisted pairs for analog signal transmission [10]. 


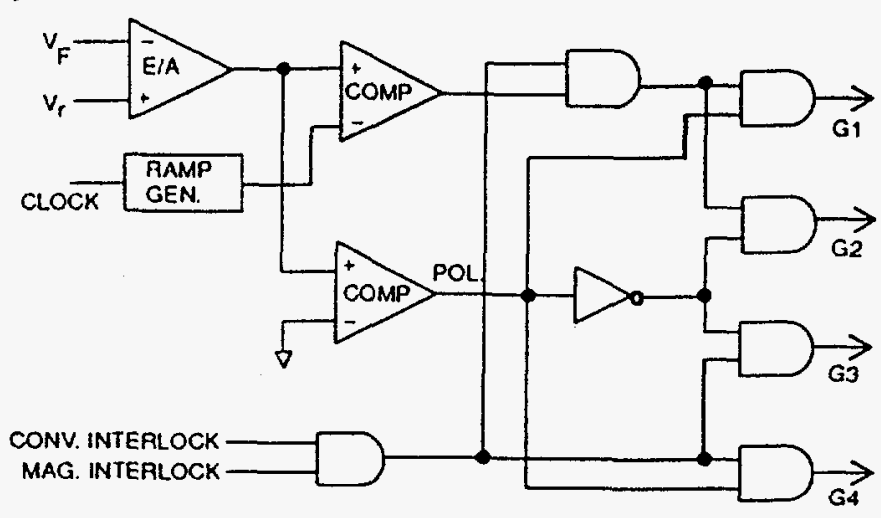

Fig. 11 : The simplified regulator circuit.

A 16-bit DAC is used for the reference signal generation. The host computer can communicate with the DAC by the PSCU or via a control computer as shown in Fig. 12. In the case where communication is by PSCU the host computer provides a current value to the PSCU which sends out a serial pulse train to count the DAC up-or-down at $250 \mathrm{kHz}$ rate. In the other case, the host computer transfers control to the control computer and setting is done with an open loop. The control computer will sense the beam position using a number of beam position monitors, and manipulate the information to compensate for the attenuation and phase delay due to the eddy current effect of the vacuum chamber. The control computer communicates directly with the DAC and can generate any new DAC setting at a $4 \mathrm{kHz}$ rate for dynamic beam correction.

\section{F. Drive Consideration}

Although the drive requirements for IGBTs are relatively simple compared with the equivalent bipolar transistors, some considerations are needed for high-current power IGBTs. The input capacitances of high-current power IGBTs are quite large; for example, approximately $20 \mathrm{nF}$ for a $200-\mathrm{A}$ IGBT. This is perhaps an order of magnitude higher than the typical TO-3 or TO-220 power IGBT, and it has a definite impact on the driver design. Moreover, when high currents are switched at high speed, the parasitic circuit inductances in a practical circuit become significant. At collector currents greater than $50 \mathrm{~A}$, a di/dt on the order of $5 \mathrm{~A} / \mathrm{ns}$ is readily achievable. At this speed, parasitic circuit inductances become firstorder determinants of performance for 200-A IGBTs. As collector current is increased, di/dt increases also. Consequently, the higher di/dt causes a larger voltage to develop actoss the parasitic circuit inductance. At turn-off, this voltage positively biases the gate, and hence increases crossover time. If the voltage developed across the parasitic circuit inductances is countered by a negative gate bias, the crossover time is decreased. Therefore, a negative gate bias of $-10 \mathrm{~V}$ is applied to all the switches during OFF time.

\section{G. Monitoring and Interlocks}

There are two Euro-cards provided in the BPS chassis for monitoring and interlocks, one for the converter (BPS) and the other for the magnet. The converter interlock card can monitor and interlock five temperatures for two IGBT modules, an input capacitor, return water, and control power supply heat sink using $\mathrm{PN}$ junctions as temperature sensors over the range of 0 to $100^{\circ} \mathrm{C}$ and three voltage signals for the magnet current, input bus, and control-power-supply failure. The magnet interlock card monitors and interlocks four temperatures for the magnet and its return water.

Each of the signals is compared to a fixed reference and the output of the comparator is used to set a flip/flop that latches the

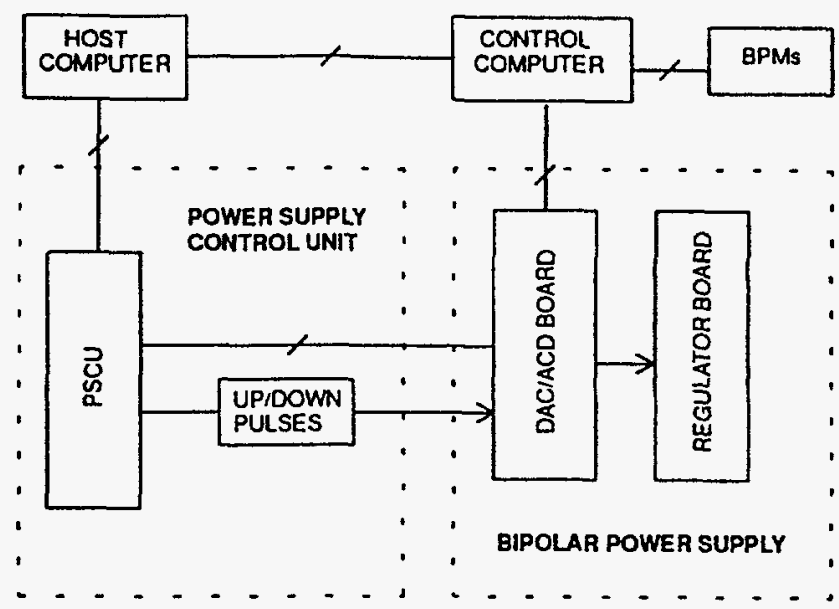

Fig. 12 : Simplified block diagram of a control scheme for storage ring correction magnets.

interlock until reset by a local or extemal reset pulse. All of these analog signals are buffered and sent to the PSCU for monitoring. The analog signals for each interlock card are ORed, and the ORed output signals are sent out to the regulator card. The ORed output signals from the converter and magnet interlock cards are combined by an AND gate to generate a shut down signal. This causes the IGBT gate signals at the output of the regulator to be clamped in case any of the failure signals activates.

\section{EXPERIMENTAL RESULTS}

Six hundred fifty-one (651) units of the 150A BPS have been manufactured, tested, and are being installed around the APS Storage Ring. Figures 13 and 14 show dc stability test results of a unit at $+150 \mathrm{Adc}$ and $-150 \mathrm{Adc}$. Note that magnet currents variations are less than $10 \mathrm{~mA}$ peak-to-peak for approximately three hours and both results are well within the specification limit $(90 \mathrm{~mA})$. A measured magnet current waveform with its command signal, which is $25 \mathrm{~Hz}$ sinusoidal at $75 \mathrm{~A}$ (peak), is shown in Fig. 15. Also, Fig. 16 shows a measured magnet current waveform with its command signal, which is $25 \mathrm{~Hz}$ sinusoidal at $75 \mathrm{~A}$ (peak) plus $+75 \mathrm{~A}$ dc current. Note that the magnet currents follow their command signals very accurately.

\section{CONCLUSION}

In this paper a current-controlled PWM bipolar power supply for a magnet load has been presented. A current control method has been shown and, based on that method, a straightforward design example of a 150A BPS is provided. Key experimental results are included. It has been shown that the conventional linear-mode power amplifier can be replaced by a properly designed PWM power amplifier for a magnet load which requires a high performance bipolar power supply.

\section{REEERENCES}

[1] Y. G. Kang, "Correction Magnet Power Supplies for APS Machine," IEEE Particle Accelerator Conference Rec., 1991, pp. 911-913.

[2] Y. G. Kang, "Design and Development of a Bipolar Power Supply for APS Storage Ring Correctors," IEEE Particle Accelerator Conference Rec., 1993, pp. 1268-1270. 


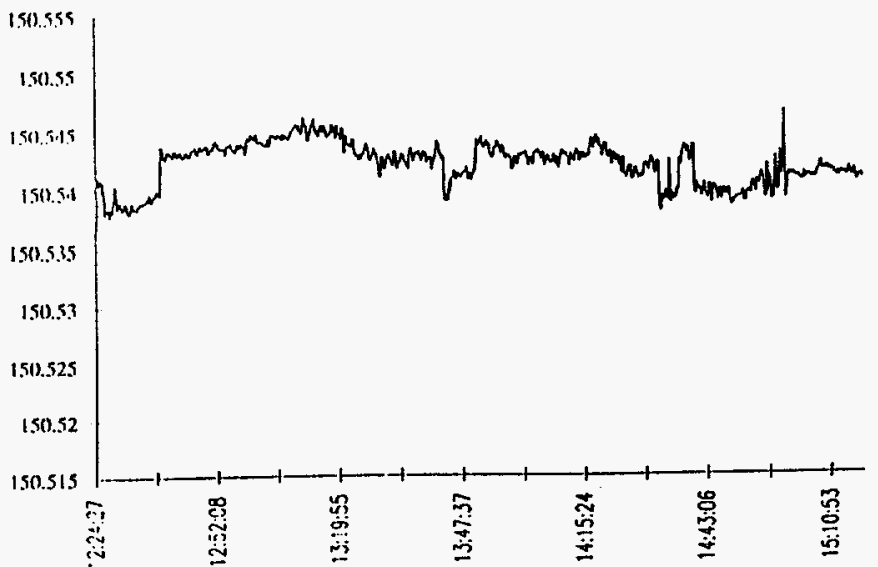

Fig. 13: DC stability test at +150 Adc.

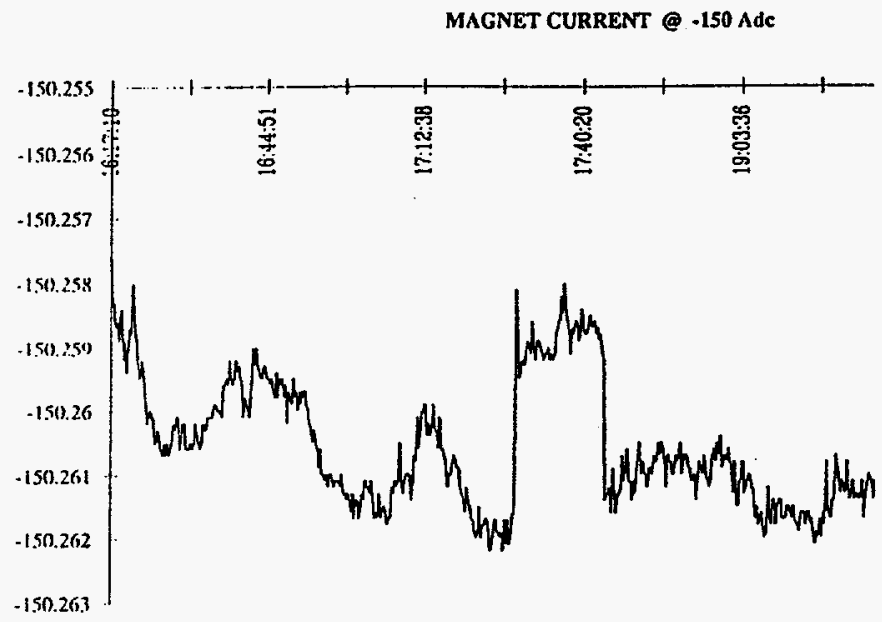

Fig. 14: DC stability test at $-150 \mathrm{Adc}$.

[3] D. M. Brod and D. W. Novotny, "Current Control of VSIPWM Inverters," IEEE Trans. on IAS, Vol. IA-21, No. 4, May/June 1985, pp. 562-570.

[4] A. Nabae, S. Ogasawara, and H. Akagi, "A Novel Control Scheme for Current-Controlled PWM Inverters," IEEE Trans. on IAS, Vol. IA-22, No. 4, July/August 1986, pp. 697-701.

[5] C. D. Schauder and R. Caddy, "Current Control of VoltageSource Inverters for Fast Four-Quadrant Drive Performance," IEEE Trans. on IAS, Vol. IA-18, No. 2, March/April 1982, pp. 163-169.

[6] A. B. Plunkett, "A Current-Controlled PWM Transistor Inverter Drive," IEEE IAS Annual Meeting Record, 1979, pp. 785-792.

[7] T. G. Habetler and D. M. Divan, "Performance Characterization of a New Discrete Pulse-Modulated Current Regulator," IEEE Trans. on IAS, Vol. IA-25, No. 6, Nov./Dec. 1989, pp. 1139-1148.

[8] T. M. Rowan and R. J. Kerkman, "A New Synchronous Current Regulator and an Analysis of Current-Regulated PWM Inverters," IEEE Trans. on IAS, Vol. IA-22, No. 4, July/August 1986, pp. 678-690.

[9] R. S. Burwen, "Parallelable PWM Amplifier," IEEE Trans. on Instrumentation and Measurement, Vol. IM-36, No. 4, December 1987, pp. 1001-1005.

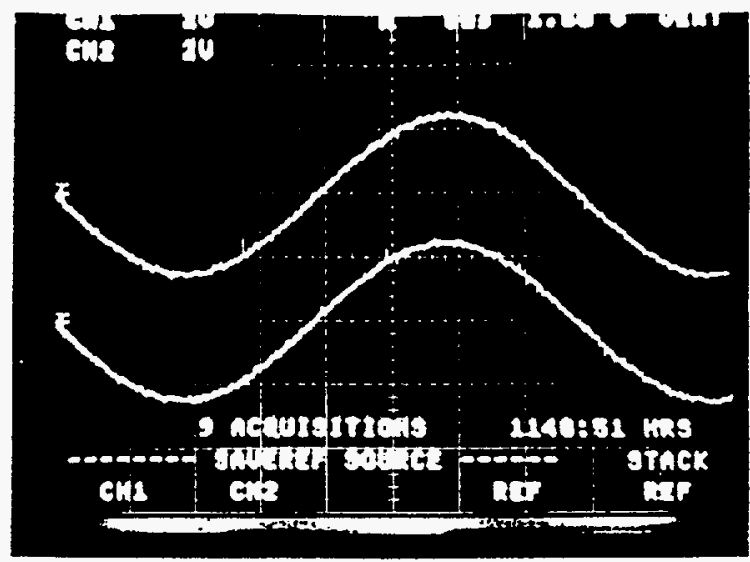

Fig. 15: Measured magnet current with its command signal. Top: Magnet current Bottom: Command signal. $\left(I_{\mathrm{ac}}=75 \mathrm{~A}_{\mathrm{pk}}, I_{\mathrm{dc}}=0 \mathrm{~A}, \mathrm{f}=25 \mathrm{~Hz}\right)$

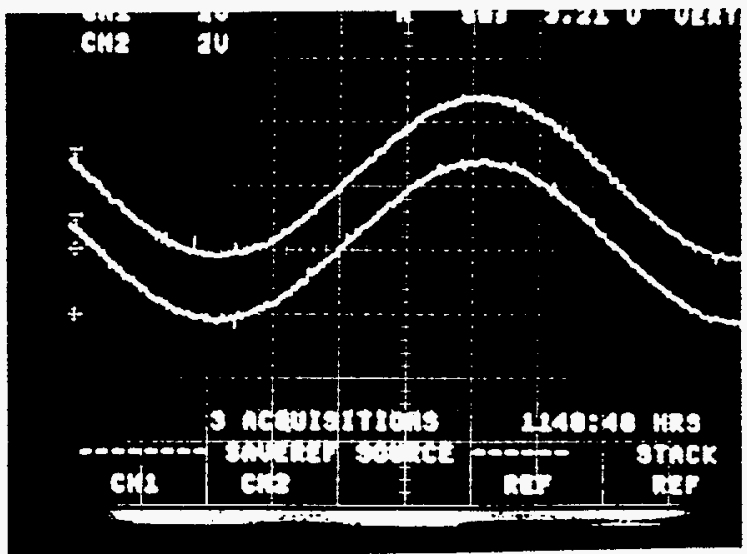

Fig. 16 : Measured magnet current with its command signal. Top: Magnet current Bottom: Command signal. $\left(I_{\mathrm{ac}}=150 \mathrm{~A}_{\mathrm{pk}}, \quad I_{\mathrm{dc}}=+75 \mathrm{~A}, \mathrm{f}=25 \mathrm{~Hz}\right)$

[10] O. D. Despe, C. Saunders, and D. G. McGhee, "Control Units for APS Power Supplies" IEEE Particle Accelerator Conference Rec., 1993, pp. 1864-1866. 